Journal of Patient-Centered

$1-28-2019$

\title{
Coordinating an Oncology Precision Medicine Clinic Within an Integrated Health System: Lessons Learned in Year One
}

\author{
Michael A. Thompson \\ Jennifer J. Godden \\ Deborah Wham \\ Antony Ruggeri \\ Michael P. Mullane \\ Amanda Wilson \\ Shamsuddin Virani \\ Scott M. Weissman \\ Brenda Ramczyk \\ Pamela Vanderwall
}

See next page for additional authors

Follow this and additional works at: https://aah.org/jpcrr

Part of the Health and Medical Administration Commons, Medical Genetics Commons, Medical

Pharmacology Commons, Neoplasms Commons, Oncology Commons, Public Health Commons, and the Translational Medical Research Commons

\section{Recommended Citation}

Thompson MA, Godden JJ, Wham D, Ruggeri A, Mullane MP, Wilson A, Virani S, Weissman SM, Ramczyk $B$, Vanderwall $P$, Weese JL. Coordinating an oncology precision medicine clinic within an integrated health system: lessons learned in year one. J Patient Cent Res Rev. 2019;6:36-45. doi: 10.17294/

2330-0698.1639

Published quarterly by Midwest-based health system Advocate Aurora Health and indexed in PubMed Central, the Journal of Patient-Centered Research and Reviews (JPCRR) is an open access, peer-reviewed medical journal focused on disseminating scholarly works devoted to improving patient-centered care practices, health outcomes, and the patient experience. 
Coordinating an Oncology Precision Medicine Clinic Within an Integrated Health System: Lessons Learned in Year One

\section{Authors}

Michael A. Thompson, Jennifer J. Godden, Deborah Wham, Antony Ruggeri, Michael P. Mullane, Amanda Wilson, Shamsuddin Virani, Scott M. Weissman, Brenda Ramczyk, Pamela Vanderwall, and James L. Weese 


\title{
Coordinating an Oncology Precision Medicine Clinic Within an Integrated Health System: Lessons Learned in Year One
}

\author{
Michael A. Thompson, MD, PhD, ${ }^{1,2}$ Jennifer J. Godden, PharmD, ${ }^{2}$ Deborah Wham, MS, CGC, ${ }^{2}$ Antony \\ Ruggeri, MD, ${ }^{2}$ Michael P. Mullane, MD, ${ }^{2}$ Amanda Wilson, MD, ${ }^{3}$ Shamsuddin Virani, MD, ${ }^{2}$ Scott M. \\ Weissman, MS, CGC, ${ }^{2,4}$ Brenda Ramczyk, BSN, ${ }^{2}$ Pamela Vanderwall, MD, ${ }^{2}$ James L. Weese, MD ${ }^{2}$ \\ ${ }^{1}$ Aurora Research Institute, Aurora Health Care, Milwaukee, WI; ${ }^{2}$ Aurora Cancer Care, Aurora Health Care, Milwaukee, WI; \\ ${ }^{3}$ Pathology, Aurora St. Luke's Medical Center, Milwaukee, WI; ${ }^{4}$ Chicago Genetic Consultants, LLC, Northbrook, IL
}

\begin{abstract}
Precision medicine is a term describing strategies to promote health and prevent and treat disease based on an individual's genetic, molecular, and lifestyle characteristics. Oncology precision medicine (OPM) is a cancer treatment approach targeting cancer-specific genetic and molecular alterations. Implementation of an OPM clinical program optimally involves the support and collaboration of multiple departments, including administration, medical oncology, pathology, interventional radiology, genetics, research, and informatics. In this review, we briefly introduce the published evidence regarding OPM's potential effect on patient outcomes and discuss what we have learned over the first year of operating an OPM program within an integrated health care system (Aurora Health Care, Milwaukee, WI) comprised of multiple hospitals and clinics. We also report our experience implementing a specific OPM software platform used to embed molecular panel data into patients' electronic medical records. (J Patient Cent Res Rev. 2019;6:36-45.)
\end{abstract}

Keywords oncology; precision medicine; integrated health system; community; genomics

\section{What Is Oncology Precision Medicine?}

Precision medicine is a buzzword in contemporary health care. Buzzwords are popular because they encapsulate complex information into simpler terminology, but they also can become overused, fail to convey appropriate complexity or nuance, and result in miscommunication. If precision medicine is defined broadly enough, it could be equated with medicine in general and loses any real meaning. More specifically, precision medicine refers to personalized therapy based on each person's DNA and other unique characteristics. The National Institutes of Health's Precision Medicine Initiative aims to gather genetic and health data on 1 million individuals to study how those characteristics may be used to prevent or treat disease. ${ }^{1}$

Correspondence: Michael A. Thompson, MD, PhD, FASCO, Aurora Research Institute, 960 N. 12th Street, Room 4111, Milwaukee, WI 53233 (michael.a.thompson@aurora.org)
The concept of oncology precision medicine (OPM) also has varied definitions and is commonly used in association with terms such as personalized medicine, genomic medicine, and individualized medicine (Table 1). Herein, we use OPM to refer to molecularly driven therapy choices - including immunotherapy based on biomarkers - applied to individuals. Health practitioners have always tried to personalize therapy by evaluating the patient as a whole (holistic) and in context with age, comorbidities, and family history. We are now increasingly using molecular information as an additional factor to define individualized treatment options.

\section{Why Pursue OPM?}

Basing cancer treatment on biomarkers or tumorspecific genetic alterations is not new in oncology. There are multiple examples of molecular biomarkers and tumor-specific genetic alterations leading to standardof-care cancer treatment: hormone receptor expression 
Table 1. Synonyms for "Precision Medicine" (used in Oncology)

Accurate medicine
Cancer genomics
Genetic medicine
Genetic profiling
Genetic testing
Individualized medicine
Molecular-guided therapy
Molecular-guided personalized medicine
Oncology precision medicine
Personalized medicine
Pharmacogenetics
Pharmacogenomics
Precision medicine
Precision oncology
Targeted therapy

and HER2 amplification in breast cancer; EGFR and $B R A F$ mutations, $A L K$ and ROS1 fusions, and PDL1 expression in lung cancer; $B R A F$ mutations in melanoma; $B R A F, K R A S$, and $N R A S$ mutations in colorectal cancer; and others. An elegant example of OPM is the development of imatinib to treat chronic myelogenous leukemia associated with the $B C R-A B L$ fusion gene. This translocation results in constitutive activity of the $A B L$ oncogene. Imatinib is a tyrosine kinase inhibitor that blocks $\mathrm{ABL}$ and reverses the malignant phenotype.

Providing OPM to patients typically involves comprehensive somatic tumor profiling and tumor biomarker analysis in those with metastatic malignancy and limited treatment choices to identify rare or unexpected, often tumor-agnostic, treatment or clinical trial options. In this setting, OPM treatment recommendations may include Food and Drug Administration (FDA)-approved therapies in a different tumor type (off-label), on- or off-protocol experimental therapies, or theoretical treatment considerations based on preclinical models.

Multiple studies have evaluated the results of OPM approaches (Table 2), ${ }^{2-12}$ and increasingly the inclusion criteria of new clinical trials include molecular alterations. Supportive evidence includes findings by Von Hoff et al, ${ }^{3}$ Radovich et al, ${ }^{4}$ and Haslem et $\mathrm{al},{ }^{8,9}$ all of whom reported gains in progression-free survival through use of molecular-based therapy. Metaanalyses by Schwaederle et al ${ }^{5,6}$ noted similar benefits to OPM approaches, including improved response rates. Conversely, criticisms of OPM are generally directed at its use in patients with metastatic, treatment-refractory disease, namely, that OPM marketing hype may take advantage of the desperation and need for hope in patients and families with advanced cancers. In an editorial published in Journal of Clinical Oncology, Howard (Jack) West noted a "fear that our current oncology community will be guilty of hubris and of overpromising what we can deliver in a realistic time line." ${ }^{\prime 13}$ West cited cautionary results from a pair of studies, the BATTLE- $2^{14}$ and the French SHIVA trial, ${ }^{2}$ the latter of which found no progression-free survival or overall survival benefit in patients treated based on molecular profiling (using drugs available at that time in France). However, Tsimberidou and Kurzrock questioned SHIVA's findings, noting study weaknesses such as the use of limited drugs and limited targets, which is not consistent with current OPM clinical trial designs. ${ }^{15}$

There are many examples of OPM clinical trials - some of historical or ongoing interest are described in Table 3 - and the National Cancer Institute (NCI) has expanded the number of OPM trials. These trials may have had and still have barriers to accrual, but as OPM panel testing becomes more pervasive, these trials are increasingly becoming the new normal. Because of the rarity of specific molecular alterations (which may be somatic or germline), randomized clinical trials do not allow for appropriately rapid evaluation of the utility of targeted medications in this setting. As such, novel ways to share information about patient response are warranted.

In 2017, Aurora Health Care (Milwaukee, WI) launched an OPM clinic to serve its integrated health system, which includes hospitals and clinics located across eastern Wisconsin and northern Illinois; the launch and implementation of this program was previously reported. ${ }^{16}$ In this follow-up work, we describe the lessons learned by clinicians, administrators, and research staff in the clinic's first year of operation for the purpose of informing other health systems of the potential outcomes an in-house OPM clinic may produce. 
Table 2. Selected Oncology Precision Medicine (OPM) References, Terms, and Findings

\begin{tabular}{|c|c|c|c|c|c|}
\hline Reference & Total & MP & $\begin{array}{l}\text { On MP } \\
\text { drug }\end{array}$ & Overall & Findings \\
\hline $\begin{array}{l}\text { Von Hoff et al } \\
\text { (2010) }\end{array}$ & 106 & 86 & 66 & + & $\begin{array}{l}\mathrm{PFS}_{\text {new }} / \mathrm{PFS}_{\text {old }} \text { ratio as an intrapatient metric; } 27 \% \text { of } \\
\text { OPM-treated patients had a PFS ratio of } 1.3 \text {. }\end{array}$ \\
\hline $\begin{array}{l}\text { Le Tourneau et } \mathrm{al}^{2} \\
(2015) \\
\text { Dureau et } \mathrm{al}^{7}(2017)\end{array}$ & 741 & 293 & 99 & - & $\begin{array}{l}\text { SHIVA study: druggable molecular alteration. No PFS } \\
\text { or OS benefit using a limited set of targets and drugs in } \\
\text { France. }\end{array}$ \\
\hline $\begin{array}{l}\text { Schwaederle et al }{ }^{5} \\
(2015)\end{array}$ & 32,149 & 8078 & 8078 & + & $\begin{array}{l}\text { Meta-analysis of } 570 \text { studies and } 32,149 \text { patients on phase } \\
\text { II, single-agent arms revealed that, across malignancies, } \\
\text { a personalized strategy was an independent predictor } \\
\text { of better outcomes and fewer toxic deaths. In addition, } \\
\text { nonpersonalized targeted therapies were associated with } \\
\text { significantly poorer outcomes than cytotoxic agents, which } \\
\text { in turn were worse than personalized targeted therapy. }\end{array}$ \\
\hline $\begin{array}{l}\text { Schwaederle et } a^{6} \\
(2016)\end{array}$ & 13,203 & - & - & + & $\begin{array}{l}\text { Meta-analysis of } 346 \text { phase I clinical trials with } 13,203 \\
\text { patients. OPM-based therapy resulted in improved ORR } \\
\text { and PFS. DNA biomarker-driven therapy had higher ORRs } \\
\text { compared to protein biomarkers. Studies that used targeted } \\
\text { agents without a biomarker-based selection strategy had } \\
\text { negligible response rates. }\end{array}$ \\
\hline $\begin{array}{l}\text { Radovich et } \mathrm{al}^{4} \\
(2016)\end{array}$ & 168 & 44 & 19 & + & $\begin{array}{l}\text { PFS ratio } \geq 1.3 \text { in } 43.2 \% \text { in MP vs } 5.3 \% \text { in non-MP treated } \\
\text { with nongenomically guided therapy }(P<0.0001) .\end{array}$ \\
\hline $\begin{array}{l}\text { Haslem et } \mathrm{al}^{8} \\
(2017) \\
\text { Haslem et al } \\
(2018)\end{array}$ & 72 & 36 & 36 & + & $\begin{array}{l}\text { Matched cohort study in the community setting. PFS } \\
\text { hazard ratio of } 0.47 \text { showing OPM benefit. MP patients had } \\
\text { lower patient costs per PFS week than the control group. } \\
2018 \text { updated data showed similar benefits for OS. }\end{array}$ \\
\hline $\begin{array}{l}\text { Ammakkanavar } \\
\text { et al }{ }^{11}(2017)\end{array}$ & 209 & 69 & 54 & $+/-$ & $\begin{array}{l}\text { Economic costs need to be considered. Panel MP tests } \\
\text { need to acknowledge prior standard-of-care testing } \\
\text { (eg, extended RAS testing in colorectal cancer). Patient } \\
\text { selection is important. There was change in management } \\
\text { for } 27 \% \text { of patients based on OPM findings. }\end{array}$ \\
\hline $\begin{array}{l}\text { Tredan et al }{ }^{12} \\
(2017)\end{array}$ & $\begin{array}{l}2490 \\
(1826 \\
\text { tested })\end{array}$ & 940 & 101 & + & $\begin{array}{l}\text { ProfiLER study. Actionable MP in } 51 \% \text { of patients, with } \\
\text { treatment recommendation in } 35 \% \text {. Most patients treated } \\
\text { derived benefit from the recommended molecular targeted } \\
\text { therapies, but these represent a minority of the whole } \\
\text { population screened. }\end{array}$ \\
\hline $\begin{array}{l}\text { Merker et al }{ }^{10} \\
(2018)\end{array}$ & - & - & - & $+/-$ & $\begin{array}{l}\text { ASCO/CAP literature review showed discordance with } \\
\text { ctDNA assays and genotyping tumor specimens. There } \\
\text { was no evidence of clinical utility and little evidence of } \\
\text { clinical validity of ctDNA assays in early-stage cancer, } \\
\text { treatment monitoring, or residual disease detection. There } \\
\text { was no evidence of clinical validity and clinical utility to } \\
\text { suggest that ctDNA assays are useful for cancer screening, } \\
\text { outside of a clinical trial. }\end{array}$ \\
\hline
\end{tabular}

ASCO, American Society of Clinical Oncology; CAP, College of American Pathologists; ctDNA, circulating tumor DNA; $M P$, molecular panel; ORR, overall response rate; OS, overall survival; PFS, progression-free survival. 
Table 3. Examples of Oncology Precision Medicine Studies

\begin{tabular}{|c|c|c|c|}
\hline Open & $\mathbf{N}$ & Sponsor & Title/NCT \\
\hline $\begin{array}{l}11 / 2006- \\
(\text { ANR) }\end{array}$ & 250 & MDACC & $\begin{array}{l}\text { BATTLE: A Biomarker-Integrated Study in Chemorefractory Patients } \\
\text { With Advanced Non-Small Cell Lung Cancer (NCT00409968) }\end{array}$ \\
\hline 2/3/18- & 217 & MDACC & $\begin{array}{l}\text { BATTLE 2: A Biomarker-Integrated Targeted Therapy Study in } \\
\text { Previously Treated Patients With Advanced Non-Small Cell Lung } \\
\text { Cancer (NCT03225664) }\end{array}$ \\
\hline $3 / 2010-$ & 1920 & QuantumLeap & $\begin{array}{l}\text { I-SPY } 2 \text { Trial: Investigation of Serial Studies to Predict Your } \\
\text { Therapeutic Response With Imaging And moLecular Analysis } 2 \\
\text { (NCT01042379) }\end{array}$ \\
\hline $3 / 2013$ & Varies & Novartis & Signature (http://www.trials.novartis.com) \\
\hline $6 / 16 / 14$ & 10,000 & $\mathrm{NCl}$ & $\begin{array}{l}\text { Lung MAP: A Biomarker-Driven Master Protocol for Previously Treated } \\
\text { Squamous Cell Lung Cancer (NCT02154490) }\end{array}$ \\
\hline 8/18/14- & 8300 & $\mathrm{NCl}$ & $\begin{array}{l}\text { ALCHEMIST: Adjuvant Lung Cancer Enrichment Marker Identification } \\
\text { and Sequencing Trial (NCT02194738) }\end{array}$ \\
\hline 8/12/15- & 6452 & $\mathrm{NCl}$ & MATCH: Molecular Analysis for Therapy Choice (NCT02465060) \\
\hline $3 / 2016-$ & 1060 & ASCO & $\begin{array}{l}\text { TAPUR: Targeted Agent and Profiling Utilization Registry } \\
\text { (NCT02693535) }\end{array}$ \\
\hline $11 / 2016-$ & 100,000 & Strata Oncology & $\begin{array}{l}\text { Profiling Biospecimens From Cancer Patients to Screen for Molecular } \\
\text { Alterations Related to Treatment Selection (NCT03061305) }\end{array}$ \\
\hline
\end{tabular}

ANR, active, not recruiting; ASCO, American Society of Clinical Oncology; MDACC, M.D. Anderson Cancer Center; $\mathrm{NCl}$, National Cancer Institute.

\section{Systemwide Oncology Overview}

Within the Aurora system, over 8000 new analytic cases are diagnosed and approximately 25,000 patients are served annually. As of this writing, the system encompasses 154 oncology physicians (including cancer-dedicated surgeons) and 11 genetic counselors. There are 19 medical oncology and 11 radiation oncology treatment locations. Approximately 180 cancer clinical trials are open or in follow-up, with more than 1100 patients on cancer clinical trials. Aurora is designated as an NCI Community Oncology Research Program (NCORP) site.

\section{OPM Clinic: Initial Progress}

After development of OPM workflow and program resources, ${ }^{16}$ the OPM clinic's first molecular tumor board (MTB) conference was held in March 2017. Although we anticipated reviewing 50 cases in the first 12 months, 100 referred patients were reviewed by November 2017 . While our program is led by a medical oncologist and oncology pharmacist, OPM patient care routinely involves several departments: nursing, research, pathology, genetic counseling, radiation oncology, and diagnostic and interventional radiology. In January 2018, a nurse program coordinator was hired as a shared full-time employee with the system's preestablished hereditary cancer prevention and management program.

The clinic has amassed a database of educational slides and articles on OPM. Initial foundational resources included published study findings by Von Hoff et al (2010), ${ }^{3}$ Radovich et al (2016), ${ }^{4}$ and Haslem et al (2017, 2018 update); ${ }^{8,9}$ the Hoosier Cancer Research Network's phase II clinical trial (BRE12-158) of genomic therapy after preoperative chemotherapy in patients with triple-negative breast cancer, ${ }^{17}$ the recent joint consensus statement by the American Society of Clinical Oncology (ASCO), Association for Molecular Pathology (AMP), and College of American 
Pathologists (CAP) on standardizing interpretation and reporting of sequence variants in cancer; ${ }^{18,19}$ and published works from Burkard et $\mathrm{al}^{20}$ and Thomas Brown ${ }^{21}$ on community-based MTBs. Additional topics continue to be explored in a journal club format as they arise during case management. Examples include Lynch syndrome and microsatellite instability testing, molecular tumor burden and DNA polymerases, and molecular alterations in prostate cancer.

\section{OPM Clinic: Operations}

As of November 2017, all comprehensive molecular panel (MP) tests performed in Aurora's oncology system are required to be ordered by OPM staff through a centralized process. This includes genomic tests from vendors Foundation Medicine (Cambridge, MA), Caris Life Sciences (Irving, TX), Paradigm Diagnostics (Phoenix, AZ), Guardant Health (Redwood City, CA), and Sysmex Inostics (Mundelein, IL), among others. The primary driver of this centralization was to reduce the financial risk to the patient or to the health system associated with inappropriate testing or lack of prior authorization. The centralized ordering process ensures that the appropriate test is performed on an appropriate patient on an appropriate tumor sample or blood specimen. This practice also allows for better understanding, oversight, and standardization of testing practices within the system.

When an oncologist decides to order one of the above tests, he or she has two options. In the first option, the oncologist enters an order template in the electronic medical record (EMR) for "Oncology Genomic Profile Comprehensive" (Figure 1A). Within this orderable, the oncologist selects the type of test to be performed and notes the preferred test specimen. These data are then deposited in a newly created field in the EMR (Figure 1B). Use of this orderable generates a task and notification for OPM staff in the EMR. The OPM team reviews the order for appropriateness and completes the test order through the requested company. If deemed inappropriate, clinic member calls the referring physician to discuss whether the test should or should not be done.

The second option is for oncologists to refer patients to the OPM clinic to coordinate the entire testing process. In that scenario, the OPM team is responsible for selecting the type of test to be conducted and the test specimen. To facilitate this, the patient meets with the OPM team at a single centralized location (within the health system) for a 1-hour visit. During this visit a physician introduces the concepts of test selection, test turnaround time, potential for test failure, financial implications of testing, risk of potential germline findings, what results could mean for treatment ("actionability"), and access to on- or off-trial treatments based on results. Following the visit a molecular test is ordered for the patient by OPM staff using either archived tissue or a new biopsy. In the case of coordinating a new biopsy, OPM staff is responsible for entry of the "Oncology Genomic Profile Comprehensive" order.

Once completed, all MP test results are routed to OPM staff electronically by the testing companies. OPM staff is then responsible for linking the PDF of the results directly to the "Oncology Genomic Profile Comprehensive" order. This allows for the tests to be stored in a consistent location within the EMR (Figure 1B) and routes results to the ordering oncologist. As of July 2018, all MP test results are automatically reviewed by the MTB. Each week, resulted cases are discussed at the OPM MTB conference. There are two main topics considered for each case: what treatment options exist for the patient based on MP results, and whether a referral for germline confirmatory testing is needed. A recommendation summary note is generated within the EMR and routed to the referring oncologist and treatment team. Treatment recommendations are classified based on levels of evidence as suggested by ASCO, AMP, and CAP. ${ }^{19}$

The primary oncologist also has the option to refer the patient to the OPM clinic after MP testing for discussion of the results. In this case the patient meets with the OPM team at the same centralized location for a 30-minute visit. The focus of this visit is on what the test results mean for the patient's treatment and whether or not there are potential germline considerations. Following case presentation to the MTB or an OPM clinic visit, the final treatment decisions are guided by the referring oncologist. However, if an oncologist decides to pursue a targeted treatment based on an MTB recommendation, OPM staff will help with acquisition of off-label medications through insurance companies or drug manufacturers. 


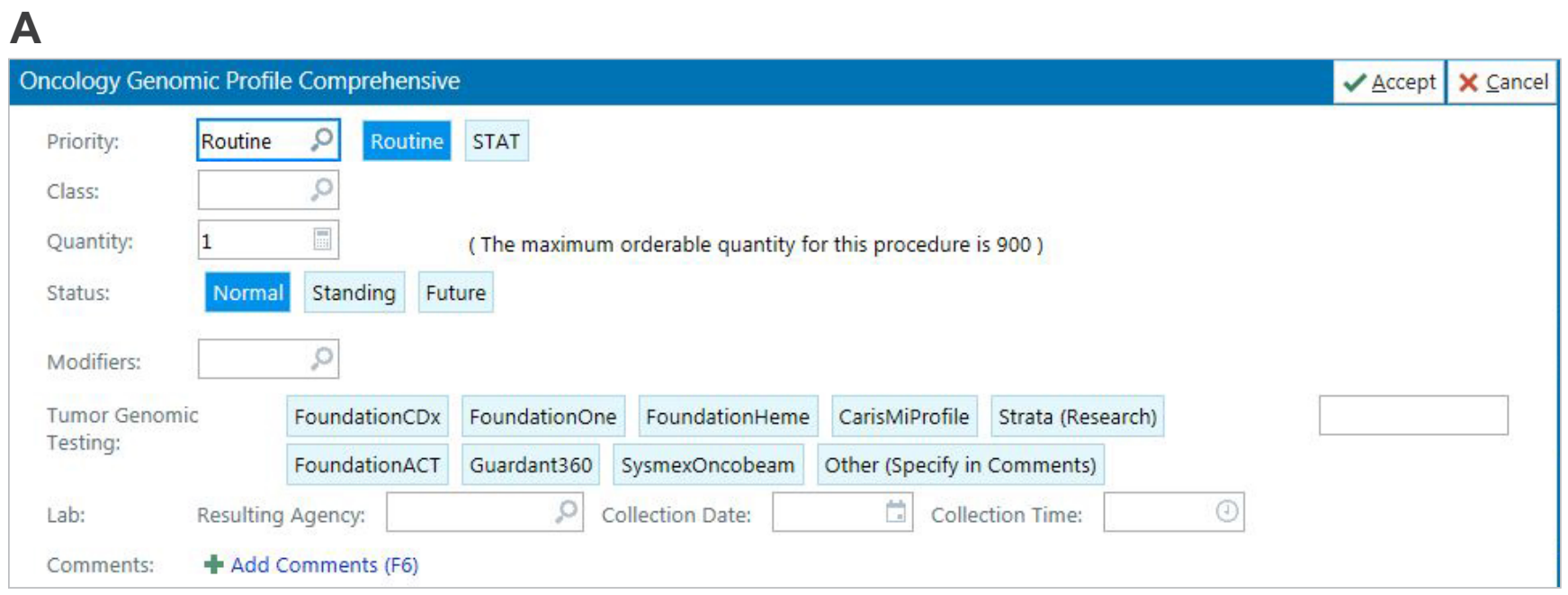

\section{B}

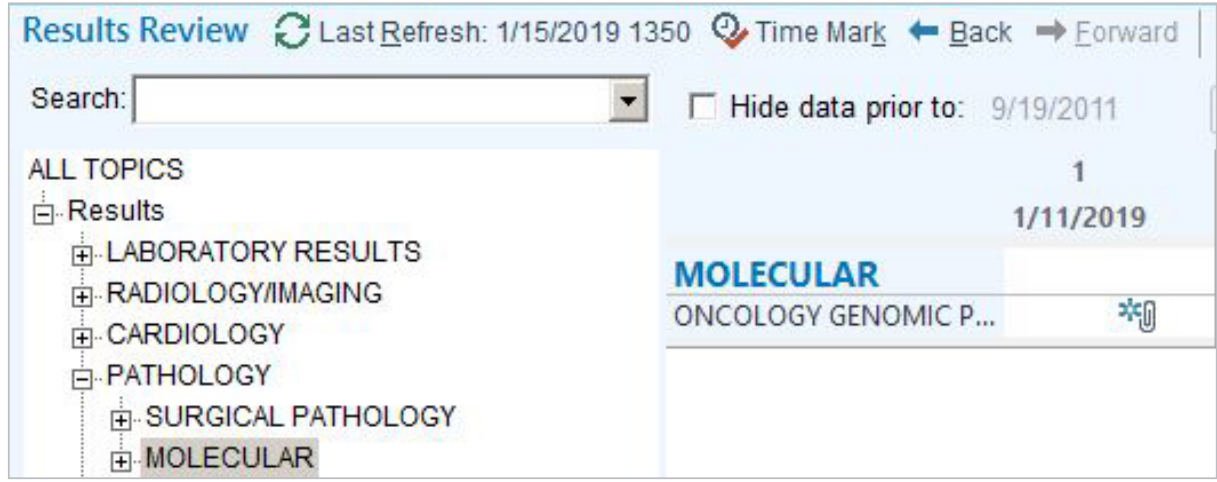

Figure 1. Electronic medical record (EMR) orderables and data.

Panel A: Orderable in the EMR for "Oncology Genomic Profile Comprehensive."

Panel B: Oncology genomic profile data is shown in the EMR under Results -> Pathology $\rightarrow$ Molecular.
If a patient will be enrolled in a clinical trial, OPM research staff will work with the research staff at the treating site to ensure a smooth transition.

\section{Biopsy and Billing}

To determine tissue source for testing, the OPM clinic works closely with pathology before, during, and after the MTB conference to discuss the diagnosis, including other molecular and nonmolecular testing not part of the MPs chosen, and to determine adequacy of tissue samples. Radiology and, in particular, interventional radiology pre-review the most current images to evaluate accessibility and the best lesion to biopsy. There remains a tension for the interventional radiologist performing a biopsy between the philosophy of "diagnosis" and getting the minimum tissue necessary to prevent complications versus obtaining adequate tissue for OPM studies. Some have suggested that rebiopsy in advanced cancer should be performed more often. ${ }^{22}$

In general, our OPM clinic makes the following recommendations: 1) New tissue is preferred over older tissue, although there are not enough data on duration of time or number or type of intervening therapies to be dogmatic; 2) Metastatic sites are preferred; 3) Solid tissue is preferred over liquid biopsies - especially given recent studies on the lack of liquid biopsy concordance with tissue, circulating tumor DNA (ctDNA), or cellfree DNA; ${ }^{10}$ and 4) Avoid zinc formalin process and bone samples, as the processing can interfere with molecular testing. ${ }^{23,24}$ In addition, tissue obtained from bone and common decalcification procedures may seriously affect DNA/RNA-based testing; whereas ethylenediaminetetracetic acid (EDTA)based decalcification may be preferred for nucleic acid 
extraction. Testing, including liquid biopsy testing, is a dynamic process that needs constant reevaluation.

MP tests ordered are screened for the Centers for Medicare \& Medicaid Services (CMS) date of service policy, or "14-day rule." 25 This regulation requires that if a biopsy or blood specimen is obtained and sent for MP testing in the 14 days following the procurement, the testing company must bill the institution that performed the biopsy and is not able to bill the patient's insurance company. As such, institutions were generally required to wait 14 days after biopsy or blood draw to submit a genomic panel test order to a test company so that patient insurance could be billed, resulting in unnecessary delays in care. As of January 1, 2018, this is no longer applicable for patients who have biopsies or blood draws performed in the outpatient setting. ${ }^{26}$ The 14-day rule is still in effect for patients with biopsies obtained in the inpatient setting and for non-next generation sequence testing procedures.

The billing process surrounding MP testing is extremely complex, and it can be difficult to convey to patients what their potential out-of-pocket costs might be. Some tests or insurance companies require prior authorization, though there is not a universal process and the means of completion is unique to each test vendor or insurance company. MP testing is typically not well-covered by insurance companies; however, on March 16, 2018, CMS finalized approval of coverage of their first MP test, ${ }^{27}$ which may change the future of this landscape. For patients without insurance coverage of MP testing, all test companies offer some degree of financial assistance. In our experience, cost to the patient has not been a significant barrier to testing. For example, of 216 Aurora patients who received testing by Foundation Medicine between July 2017 and July 2018 and who completed financial assistance applications, 163 were rewarded 100\% financial assistance while an additional 20 patients received either $80 \%$ or $90 \%$ coverage.

\section{Role of OPM Data Software}

It is possible to conduct an OPM MTB review with paper and pencil or an off-the-shelf electronic database. However, we felt it was critical to have the molecular data embedded in the EMR in a way that they would be retrievable during the course of a patient's treatment and follow-up period. Therefore, our OPM clinic purchased a software product (Syapse, San Francisco, CA) to allow data transfer from different testing companies or labs, conversion of PDF data into discrete data points, and access to the product's sharing network, which compiles outcomes data (such as drug response) from patients at all organizations utilizing the product. ${ }^{16}$ A fully functional sharing network could allow interoperability across participating health systems by providing uniform structured information to allow for aggregating cancer genomics data. ${ }^{28}$ Our perceived shortcomings of Syapse's current platform include an inability to embed the discrete data directly into the EMR and the slow availability of a clinical trials matching program.

An MP's "reported actionability" by molecular testing companies is often not realized as "pragmatic actionability" in the real-world setting. A normalized data collection and analysis process allows evaluation of concordance among MP therapy recommendations, treatment orders, treatment rate, and clinical outcomes. ${ }^{29}$ This should aid in understanding barriers to implementation of OPM as well as identifying areas of heterogeneous value in OPM testing. We have experimented with various reporting metrics for internal and external use. Figure 2 depicts a CONSORTlike diagram of MP data flow using data from 2018. Although a significant proportion of our patients are not receiving the recommended treatment (frequently due to the decision to save therapies for later potential progression), this is not unexpected compared with other OPM programs. ${ }^{\text {ef. } 20}$

Other metrics can evaluate utilization of MP tests, stage use, and physicians ordering the test.

\section{Future Program Goals}

With our OPM centralized ordering system, weekly OPM MTB conference, and OPM clinic now established, we are looking to take the next steps. In the future we intend to evaluate:

- Multiple outcomes metrics such as response rate, progression-free survival ratio, health economic data, and more. We also want to look at what happened after we moved from a referral system to a full "denominator" of testing to be more systemic in nature. 
ONCOLOGY PRECISION MEDICINE MTB AND CLINIC OUTCOMES 2018

\begin{tabular}{|c|c|c|c|c|c|}
\hline Total patients presented to MTB & 246 & & & & \\
\hline & & & & \multicolumn{2}{|l|}{ Reason not receiving: } \\
\hline & & & & Future treatment option & $59.2 \%$ \\
\hline \multirow{2}{*}{$\begin{array}{l}\% \text { patients with } 1+\text { MTB treatment } \\
\text { recommendation }\end{array}$} & 112 & \multirow{2}{*}{$\begin{array}{c}\% \text { NOT receiving } \\
\text { recommended }\end{array}$} & \multirow{2}{*}{$\begin{array}{c}76 \\
67.9 \% \\
\end{array}$} & No further treatment & $23.7 \%$ \\
\hline & $45.5 \%$ & & & Provider choice & $5.3 \%$ \\
\hline & & & & Unable to obtain off-label & $2.6 \%$ \\
\hline & & & & Unable to enroll in trial & $7.9 \%$ \\
\hline \multirow{2}{*}{$\begin{array}{l}\text { \% patients receiving any MTB } \\
\text { recommended treatment }\end{array}$} & 36 & & & Lost to follow-up & $1.3 \%$ \\
\hline & $14.6 \%$ & & & & \\
\hline
\end{tabular}

\# patients receiving recommended treatment:

\begin{tabular}{|c|c|}
\hline Immunotherapy & 9 \\
\hline PARP inhibitor & 6 \\
\hline BRAF combination therapy & 5 \\
\hline MTOR inhibitor & 5 \\
\hline Clinical trial & 3 \\
\hline Anti-EGFR therapy & 3 \\
\hline Anti-HER2 therapy & 3 \\
\hline Anti-FGFR therapy & 1 \\
\hline Anti-KIT therapy & 1 \\
\hline MEK inhibitor & 0 \\
\hline CDK4/6 inhibitor & 0 \\
\hline PIK3CA inhibitor & 0 \\
\hline Anti-MET therapy & 0 \\
\hline Total patients on treatment & 36 \\
\hline
\end{tabular}

Figure 2. Oncology precision medicine molecular tumor board (MTB) and clinic outcomes at the reviewed health system in 2018.

- Actionable alterations versus variants of unknown significance, or VUS (ie, variants that may have significance but are not profiled as such in databases ${ }^{29}$ ).

- Genetic counseling referral patterns.

- Alteration allele percentages as a surrogate for the gold standard of matched host and tumor DNA.

- Deeper dive into selected individual cases, including expanded testing such as exome or whole genome sequencing and other omics (RNA, protein, methylation, microbiome) with sequential testing, to improve our understanding of systems biology and mechanisms of resistance.

- Patient-centered feedback about the OPM process.

- Clinical decision support to systematize beyond the MTB and beyond one health system.

- Expansion into noncancer areas such as cardiology, obstetrics, and behavioral health.

\section{Conclusions}

There are no prospective randomized controlled trials establishing oncology precision medicine-based treatment decisions as superior to routine care. However, the most successful OPM treatments - targeted therapy for non-small cell lung cancer or melanoma, tumoragnostic immunotherapy for microsatellite unstable cancers, etc - are quickly adopted into standard of care. There is considerable heterogeneity in clinical results of studies evaluating OPM strategies. The ratio of progression-free survival on MP-selected therapy $\left(\mathrm{PFS}_{\text {new }}\right)$ to progression-free survival prior to MPselected therapy $\left(\mathrm{PFS}_{\text {old }}\right)$ is a controversial intrapatient metric for evaluation of OPM treatment benefit. There is considerable controversy in the oncology community regarding the value of, and future of, OPM, somewhat sparked by its undeniably considerable visibility and 
often-exaggerated benefits, particularly when used as a marketing tool.

That said, we created an OPM clinic and associated molecular tumor board to attempt to achieve the greatest possible value from OPM-based treatment. Through this centralized approach, we hope to ensure the appropriate patient is tested at the appropriate time and testing is performed on the appropriate specimen. Internal expertise for prioritizing therapeutic targets and obtaining off-label or experimental therapeutics has developed since the clinic's launch. Identification of FDA-approved therapies and clinical trial options has grown more efficient, as has evaluation for germline variants that may have treatment implications for the patient and clinical implications for family members. Finally, we also have been able to minimize financial exposure for the patient and institution.

\section{Patient-Friendly Recap}

- Hope: Initial lessons learned from operating an oncology precision medicine clinic inspire optimism in this approach to identifying targeted cancer therapies.

- Hype: There also is the potential that marketing hype and genuine enthusiasm among providers may mislead patients. Expectations should be tempered with data.

- Be curious: Ask questions regarding available care options.

- Be critical: Understand the evidence behind decisions and potential benefit; understand the risk of biopsy and potential financial burden.

\section{Acknowledgments}

Initial startup funding for this oncology precision medicine clinic was supported in part by the Vince Lombardi Cancer Foundation (Milwaukee, WI).

\section{Author Contributions}

Study design: all authors. Data acquisition or analysis: all authors. Manuscript drafting: all authors. Critical revision: all authors.

\section{Conflicts of Interest}

None of the authors have received honoraria from any vendor referenced within this work. Scott Weissman founded the genetics company Chicago Genetic Consultants, LLC, and also owns stock in Genome Medical Services (San Francisco, CA).

\section{References}

1. Genetics Home Reference (National Institutes of Health). What is the Precision Medicine Initiative? Last reviewed 2015 Apr. https://ghr.nlm.nih.gov/primer/precisionmedicine/initiative. Accessed May 11, 2018.

2. Le Tourneau C, Delord JP, Gonçalves A, et al. Molecularly targeted therapy based on tumour molecular profiling versus conventional therapy for advanced cancer (SHIVA): a multicentre, open-label, proof-of-concept, randomised, controlled phase 2 trial. Lancet Oncol. 2015;16:1324-34. CrossRef

3. Von Hoff DD, Stephenson JJ Jr, Rosen P, et al. Pilot study using molecular profiling of patients' tumors to find potential targets and select treatments for their refractory cancers. J Clin Oncol. 2010;28:4877-83. CrossRef

4. Radovich M, Kiel PJ, Nance SM, et al. Clinical benefit of a precision medicine based approach for guiding treatment of refractory cancers. Oncotarget. 2016;7:56491-500. CrossRef

5. Schwaederle M, Zhao M, Lee JJ, et al. Impact of precision medicine in diverse cancers: a meta-analysis of phase II clinical trials. J Clin Oncol. 2015;33:3817-25. CrossRef

6. Schwaederle MC, Zhao MM, Lee JJ, et al. Impact of precision medicine in refractory malignancies: a meta-analysis of 13,203 patients in phase I clinical trials. (abstr.) J Clin Oncol. 2016;34(15_suppl):11520. CrossRef

7. Dureau S, Ricci F, Alt M, et al. SHIVA: randomized phase II trial comparing molecularly targeted therapy based on tumor molecular profiling versus conventional therapy in patients with refractory cancer - overall survival (OS) analysis. (abstr.) J Clin Oncol. 2017;35(15_suppl):11515. CrossRef

8. Haslem DS, Van Norman SB, Fulde G, et al. A retrospective analysis of precision medicine outcomes in patients with advanced cancer reveals improved progression-free survival without increased health care costs. J Oncol Pract. 2017;13:e108-19. CrossRef

9. Haslem DS, Chakravarty I, Fulde G, et al. Precision oncology in advanced cancer patients improves overall survival with lower weekly healthcare costs. Oncotarget. 2018;9:12316-22. CrossRef

10. Merker JD, Oxnard GR, Compton C, et al. Circulating tumor DNA analysis in patients with cancer: American Society of Clinical Oncology and College of American Pathologists joint review. J Clin Oncol. 2018;36:1631-41. CrossRef

11. Ammakkanavar NR, Bedano PM, Agarwala AK, et al. Next generation sequencing in community oncology practice: beneficial or economical burden? (abstr.) J Clin Oncol. 2017;35(15_suppl):102. CrossRef

12. Tredan O, Corset V, Wang Q, et al. Routine molecular screening of advanced refractory cancer patients: an analysis of the first 2490 patients of the ProfiLER study. (abstr.) J Clin Oncol. 2017;35(18_suppl):LBA100. CrossRef

13. West HJ. Can we define and reach precise goals for precision medicine in cancer care? J Clin Oncol. 2016;34:3595-6. CrossRef

14. Papadimitrakopoulou V, Lee JJ, Wistuba II, et al. The BATTLE-2 study: a biomarker-integrated targeted therapy study in previously treated patients with advanced non-smallcell lung cancer. J Clin Oncol. 2016;34:3638-47. CrossRef

15. Tsimberidou AM, Kurzrock R. Precision medicine: lessons learned from the SHIVA trial. Lancet Oncol. 2015;16:e579-80. CrossRef

16. Thompson MA, Godden JJ, Weissman SM, et al. Implementing an oncology precision medicine clinic in a large community health system. Am J Manag Care. 2017;23(10 Spec No):SP425-7. 
17. ClinicalTrials.gov. Randomized controlled trial of genomically directed therapy in patients with triple negative breast cancer. Last update posted 2018 Feb 8.

18. ASCO in Action. ASCO, AMP, and CAP issue new joint consensus statement to standardize interpretation and reporting of sequence variants in cancer (press release). Issued 2016 Dec 16). https://www.asco.org/advocacypolicy/asco-in-action/joint-guidelines-standardize-sequencevariants-in-cancer. Accessed May 11, 2018.

19. Li MM, Datto M, Duncavage EJ, et al. Standards and guidelines for the interpretation and reporting of sequence variants in cancer: a joint consensus recommendation of the Association for Molecular Pathology, American Society of Clinical Oncology, and College of American Pathologists. J Mol Diagn. 2017;19:4-23. CrossRef

20. Burkard ME, Deming DA, Parsons BM, et al. Implementation and clinical utility of an integrated academic-community regional molecular tumor board. JCO Precis Oncol. 2017 Jul 5 [Epub ahead of print]. CrossRef

21. Brown TD. Role of community-based genomics programs. JCO Precis Oncol. 2017 Jul 5 [Epub ahead of print]. CrossRef

22. Jekunen AP. Role of rebiopsy in relapsed non-small cell lung cancer for directing oncology treatments. J Oncol. 2015;2015:809835. CrossRef

23. Choi SE, Hong SW, Yoon SO. Proposal of an appropriate decalcification method of bone marrow biopsy specimens in the era of expanding genetic molecular study. J Pathol Transl Med. 2015;49:236-42. CrossRef
24. Schrijver WA, van der Groep P, Hoefnagel LD, et al. Influence of decalcification procedures on immunohistochemistry and molecular pathology in breast cancer. Mod Pathol. 2016;29:1460-70. CrossRef

25. Government Publishing Office. Code of Federal Regulations Title 42, Section 414.510 (Laboratory date of service for clinical laboratory and pathology specimens). Revised 2011 Oct 1 . https:// www.gpo.gov/fdsys/pkg/CFR-2011-title42-vol3/pdf/CFR-2011title42-vol3-sec414-510.pdf. Accessed May 11, 2018.

26. Centers for Medicare \& Medicaid Services. Laboratory date of service policy. Last modified 2018 Feb 27. https://www. cms.gov/Medicare/Medicare-Fee-for-Service-Payment/ ClinicalLabFeeSched/Clinical-Lab-DOS-Policy.html. Accessed May 11, 2018.

27. Centers for Medicare \& Medicaid Services. Decision memo for next generation sequencing (NGS) for Medicare beneficiaries with advanced cancer (CAG-00450N). Issued 2018 Mar 16. https://www.cms.gov/medicare-coverage-database/details/ncadecision-memo.aspx?NCAId=290. Accessed August 27, 2018.

28. Tittel PD, Zaman A, Shima JE, et al. Successful automated normalization of cancer outcomes for half a million patients across four disparate health systems. (abstr.) J Clin Oncol. 2018;36(15_suppl):e18763. CrossRef

29. Thompson MA, Zaman A, Winzeler AM, et al. Reportable actionability versus pragmatic actionability: implementing precision medicine at three large health systems. (abstr.) J Clin Oncol. 2018;36(15_suppl):6539. CrossRef

(C) 2019 Aurora Health Care, Inc. 